\title{
Fracture Strength of Teeth Restored with Ceramic Inlays and Overlays
}

\author{
Susana MORIMOTO ${ }^{1}$ \\ Glauco Fioranelli VIEIRA ${ }^{1}$ \\ Carlos Martins AGRA ${ }^{1}$ \\ Newton SESMA ${ }^{2}$ \\ Carlos GIL ${ }^{2}$
}

${ }^{1}$ Department of Restorative Dentistry, Dental School, University of São Paulo, São Paulo, SP, Brazil

${ }^{2}$ Department of Prosthodontics, Dental School, University of São Paulo, São Paulo, SP, Brazil

\begin{abstract}
This study evaluated the fracture strength of teeth restored with bonded ceramic inlays and overlays compared to sound teeth. Thirty sound human maxillary premolars were assigned to 3 groups: 1- sound/unprepared (control); 2- inlays and 3- overlays. The inlay cavity design was Class II MOD preparation with an occlusal width of $1 / 2$ of the intercuspal distance. The overlay cavity design was similar to that of the inlay group, except for buccal and palatal cusp coverage The inlay and overlay groups were restored with feldspathic porcelain bonded with adhesive cement. The specimens were subjected to a compressive load until fracture. Data were analyzed statistically by the Kruskal-Wallis test at $5 \%$ significance level. The fracture strength means $(\mathrm{KN})$ were: Sound/unprepared group $=$ 1.17 , Inlay group $=1.17$, and Overlay group $=1.14$. There were no statistically significant differences $(\mathrm{p}>0.05)$ among the groups. For inlays and overlays, the predominant fracture mode involved fragments of one cusp ( $70 \%$ of simple fractures). The fracture strength of teeth restored with inlay and overlay ceramics with cusp coverage was similar to that of intact teeth.
\end{abstract}

Key Words: ceramic, inlay, overlay, fracture, cusp coverage.

\section{INTRODUCTION}

Cusp coverage seems to be the most controversial point in the final design of cavity preparation for posterior teeth. The mechanical properties of the restorative material would be considered before choosing the cavity design (1). The advent of bonded restorations allowed several different designs for inlays, onlays and overlays (2-6) due to the reinforcement of the dental structure (2,710). Design type of tooth preparation is also essential for esthetics, resistance and fit of the ceramic restoration.

Cavity preparation is directly related to decrease of cusp stiffness. The depth and width may affect cusp deflection and tooth fracture strength $(7,11-13)$. The use of ceramics with adhesive techniques permits the preservation of tooth structure and more esthetic restorations in posterior teeth (5-6,14-17). These types of restoration can be classified as inlays (no cusp is covered), onlays (at least one cusp is not covered) and overlays (all cusps are covered) (10). Metallic inlays only replace lost tooth structure and do not protect the remaining cusps and the inlay itself acts as a wedge between buccal and lingual cusps. Metallic overlays cover all cusps of the tooth, avoiding its deflection, producing a uniform distribution of stress and preventing cusp separation (18-19). Total occlusal coverage in metallic overlays has been used when more than a half of the buccolingual width of the crown is involved in the isthmus form of the mesioocclusal-distal (MOD) restoration (11,18-19). Bonded inlay restorations increase the strength of the remaining dental structure and reduce cusp deflection $(6,10,14,16)$.

Several tooth preparation designs for esthetic restorations have been proposed based on the traditional design for cast restorations, changing only the thickness and the divergence of walls $(1,8,10)$. Although cusp coverage has been extensively investigated $(5-6,18$ - 
20), ceramic restorations remain a challenge because their properties are different from those of metal and adhesion is an important factor $(5-6,15)$. Few studies have compared compressive strength of ceramic inlays, onlays and overlays (3,5-6).

This study compared the fracture strength and the failure mode of sound teeth and teeth subjected to inlay and overlay porcelain restoration procedures. The null hypothesis tested was that there is no significant difference in fracture strength between sound teeth and teeth restored with ceramic inlays and overlays.

\section{MATERIAL AND METHODS}

Thirty recently extracted sound human maxillary premolars were stored in distilled water at room temperature for 3 months, from the day of extraction until testing. The teeth were free of caries, cracks and restorations. Any calculi and soft tissue deposits were removed with a hand scaler (Gracey currette; Hu-Friedy, Chicago, IL, USA) and pumice prophylaxis. In order to homogenize the groups, all teeth $(n=30)$ were previously standardized regarding the buccolingual width, according to parameters mentioned in the literature (12). Measurements were done with a digital caliper accurate to the nearest $0.01 \mathrm{~mm}$ (Mitutoyo America Corporation, Aurora, IL, USA). Then, the teeth were assigned to 3 groups ( $\mathrm{n}=10)$ according to the similarity of tooth size. Once each tooth size was determined, the buccolingual width means were calculated and standard deviation (SD) was obtained for each group. The mean buccolingual widths (in $\mathrm{mm}$ ) for the three groups were as follows: Sound/unprepared group: $9.70 \pm 0.65$; Inlay group: 9.58 \pm 0.58 ; Overlay group: $9.40 \pm 0.58$.

The selected teeth were mounted with their roots embedded in autopolymerized acrylic resin (Jet; Clássico Produtos Odontológicos Ltda., São Paulo, Brazil) in plastic rings (Buehler Sampl-Kup; Buehler Ltd, Lake Bluff, IL, USA), with the cementoenamel junction $1 \mathrm{~mm}$ above the acrylic resin surface. The teeth were positioned in the center of the ring with the aid of the vertical arm of a prosthetic surveyor (Bioart; São Carlos, Brazil).

Three impressions were taken with a vinyl polysiloxane material (Elite H-D-light body; Zhermack SpA, Italy) before specimen preparation. One silicone impression was poured with die stone (Velmix; Kerr, Romulus, MI, USA). The other impressions were cut in a mesiodistal or buccolingual direction, and served as guides for fabrication of the ceramic restorations (Fig. 1A). In the sound/unprepared group, the teeth were kept intact for comparison purposes. In the inlay group, Class II MOD preparations were made with $1 / 2$ of the intercuspal distance wide, $2 \mathrm{~mm}$ deep pulpally, and 4 mm deep proximal boxes. In the overlay group, Class II MOD preparations were $1 / 2$ of the intercuspal distance wide, buccal and lingual cusp coverages, with a reduction of $1.5 \mathrm{~mm}$ for the buccal cusp and $2 \mathrm{~mm}$ for the lingual cusp, $2 \mathrm{~mm}$ deep pulp wall, and $2 \mathrm{~mm}$ deep proximal boxes. Both cavity types (inlays and overlays) were prepared with rounded internal angles, with a divergence between the walls of 6 to $15^{\circ}$ and with margins with $90^{\circ}$ cavosurface angles. Proximal boxes (inlays and overlays) were made with special burs (Sonicsys; Kavo Dental GmbH, Germany) (Fig. 1B). The occlusal box and other reductions were made with a water-cooled high-speed handpiece (Kavo Dental $\mathrm{GmbH}$ ) and diamond burs (\#836KR; GEBR, Brasseler, Germany), which were replaced after 2 preparations.

Impressions of the prepared teeth were taken with an addition silicone impression material (Elite H-Dlight body; Zhermack SpA, Badia Polesine, Italy) in an individual plastic tray, and working dies were poured in investment (Ducera-lay Superfit; Degussa, South Plainfield, NJ, USA) in a vacuum mixer (Multivac 4; Degussa). Feldspathic porcelain restorations (Symbio ceram; Degussa) were produced according to the manufacturer's instructions. The internal fit of the restoration was evaluated with the light body impression material (Elite H-D- light body; Zhermack SpA). The silicone pellicle showed thin or perforated areas that were marked with a pencil and restoration areas corresponding to these marks were removed with a medium grit, round diamond bur (\#801.314.012; GEBR, Brasseler) in highspeed handpiece (air/water spray cooled). Restorations were measured with a thickness gauge (Wilcos, Rio de Janeiro, RJ, Brazil) and an occlusal thickness of 1.5 to $2 \mathrm{~mm}$ was considered as adequate.

Inlay and overlay restorations were treated with a 10\% hydrofluoric acid solution (Dentsply, York, PA, USA) for $3 \mathrm{~min}$, rinsed, ultrasonicated (Sercon; Mogi das Cruzes, SP, Brazil) and air dried. The etched porcelain surface was treated with a silane agent (3M Scothbond ceramic primer; 3M/ESPE, St. Paul, MN, USA) for 5 min and air dried. The teeth were acid etched for $15 \mathrm{~s}$ with a $37 \%$ phosphoric acid gel (3M/ESPE) and rinsed with water for $30 \mathrm{~s}$. The rinsed surface was left moist. 
An activator (Scothbond Activator; 3M/ESPE) was applied and air dried for $5 \mathrm{~s}$. A primer (Scothbond Primer; $3 \mathrm{M} / \mathrm{ESPE}$ ) was applied and air dried for $5 \mathrm{~s}$. A catalyst (Scothbond Catalyst; 3M/ESPE) was applied to the teeth and restorations. A dual-cure cement (Opal; 3M/ESPE) was hand mixed and applied to both prepared teeth and ceramic restorations. After seating of restorations on the prepared teeth, excess cement was removed with a scaler. The cement was polymerized with a halogen curing light (Optilux 400; Demetron, Kerr Corp., Danbury, $\mathrm{CT}$, USA; $400 \mathrm{~mW} / \mathrm{cm}^{2}$ ) for $40 \mathrm{~s}$ in the buccal, lingual and occlusal sides. Finishing burs and silicone tips (set 4055; GEBR, Brasseler) were used to remove excess cement and provide smooth surfaces.

After storage in distilled water at room temperature for $48 \mathrm{~h}$, the teeth were subjected to a thermocycling regimen of 700 cycles between $5^{\circ} \mathrm{C}$ and $55^{\circ} \mathrm{C}$ remaining
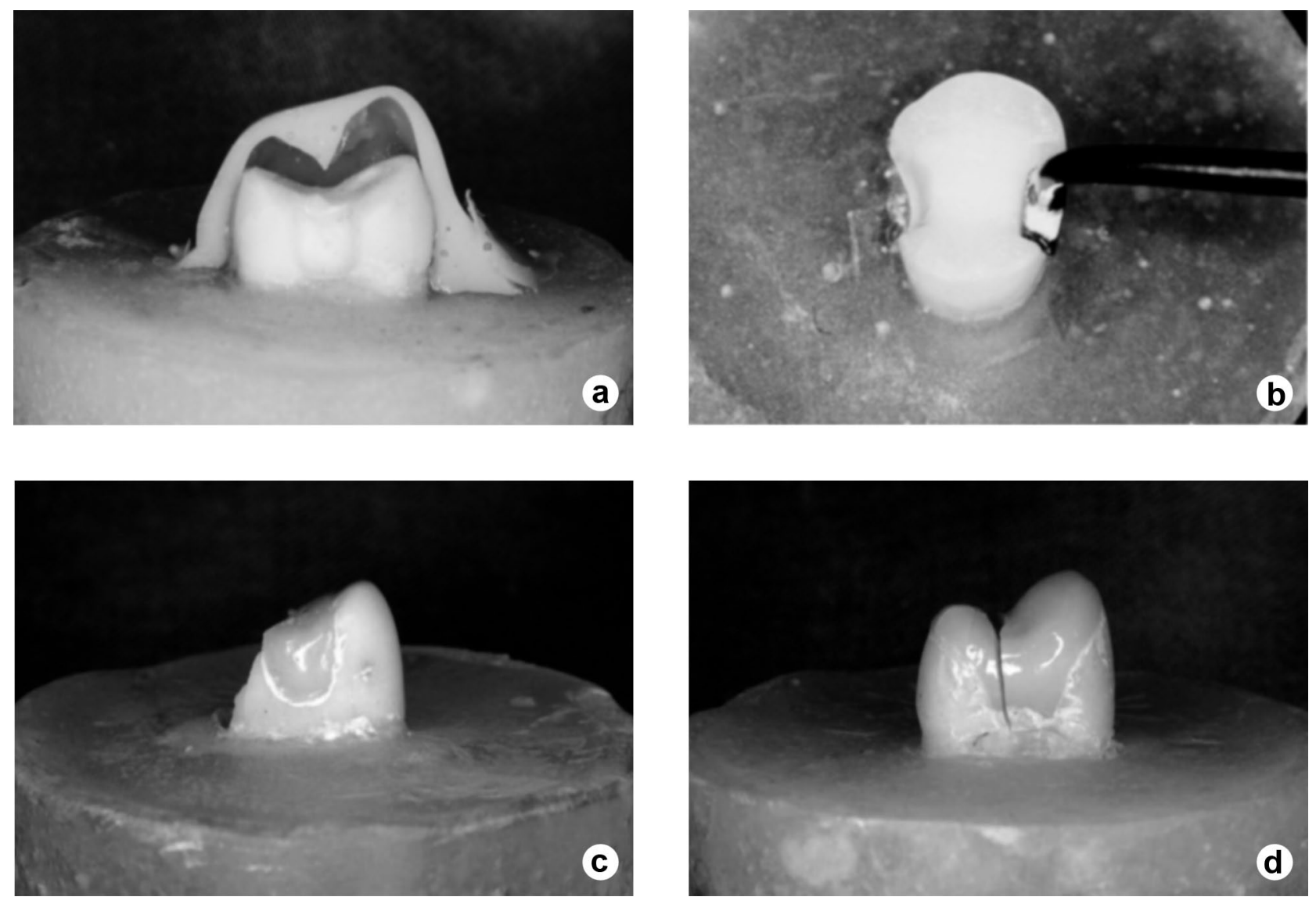

Figure 1. Panel of photographs of illustrating specimen fabrication and failure modes. A: Impression used as guideline for the preparation and manufacturing of the ceramic restoration; B: Proximal boxes prepared with special burs (Sonicsys); C: Moderate fracture (Mode II) - complete fracture of one cusp; D: Catastrophic fracture (Mode III) - longitudinal fracture running towards dental root. 
As a non-normal distribution of data was observed, the non-parametric Kruskal-Wallis test was used at a significance level of $5 \%$.

\section{RESULTS}

The fracture strength means (KN) and standard deviations for the three groups were as follows: sound/ unprepared group: $1.17 \pm 0.46$; inlay group: $1.17 \pm 0.30$; overlay group: $1.14 \pm 0.25$.

There were no significant differences $(p>0.05)$ in the fracture strength of the groups (intact/inlays/ overlays). Regarding the failure modes, $30 \%$ of the intact teeth had partial lingual cusp fractures (Mode I) and $70 \%$ presented complete cusp fractures (Mode II). Among the teeth restored with inlays, the most common failure pattern was Mode I, which occurred in $70 \%$; the remaining 30\% were total cusp fractures (Mode II). For teeth restored with overlays, $70 \%$ were simple fractures (Mode I), 10\% were moderate fractures (Mode II) and $20 \%$ were severe fractures (Mode III).

\section{DISCUSSION}

This study evaluated the importance of ceramics, resin cements and cavity design in strengthening restored teeth. Cavity preparation should primordially be based on the preservation of dental structure and physical properties of the restorative materials. The parameters for cavity design should also be in accord with principles of adaptation, resistance and retention, occlusion and esthetics $(1,5-8,13,17,19)$. Adhesive luting procedures can reinforce teeth and minimize deleterious effects of cusp flexure, thus increasing crown stiffness as an outcome of adhesive effects, cohesive resistance and stress distribution (4,7,9-10,14-17).

Studies investigating effects of cavity preparation on the potential of tooth fracture due to occlusal compressive load (5-6,11-17), using photoelastic and finite element stress analysis $(4,19,20)$, were decisive in changing cavity design, questioning the philosophies that recommended an occlusal box width of one-third or one-fourth of the intercuspal distance. An in vivo study assessing the influence of cavity preparation on tooth fracture found that $94 \%$ of fractures occurred in prepared teeth when the width of the isthmus was $1 / 3$ or more of the intercuspal distance. Conversely, intact teeth and conservative preparations produced fewer fractures
(12). Several studies proposed that teeth with a loss of structure greater than $1 / 3$ of the intercuspal distance should have cusps covered with metallic restorations in order to lessen the wedge effect and the cusp flexure $(11,12,18,19)$.

The findings of the present study are consistent with those of previous investigations $(2,9,12)$, which consider that acid etching and adhesive techniques do reinforce dental structure in a way that the stiffness values of restored teeth approximate the values of sound teeth. Ceramic inlays with $1 / 2$ or $1 / 3$ of the intercuspal distance, luted with resin cements, can recover tooth strength near that of intact teeth $(9,10)$. Based on the literature $(9,10)$ and supported by the results of the present study, it may be questioned if Class II MOD preparations with 1/2 of the intercuspal distance did require cusp coverage for protection when bonded ceramic restorations were used.

Burke et al. (2) compared prepared teeth restored with indirect composite resin (inlays, onlays and overlays) to intact teeth compressively loaded to fracture and found greater fracture loads for onlays and overlays than for inlays. These results are divergent from those obtained in the present investigation and can be explained by the difference between composite and ceramic properties. Composites have a $57 \%$ greater ability to absorb impacts than ceramics $(3,4)$. However, cusp coverage with composite resin is clinically questioned in regard to composite wear, staining and weaker adhesion to teeth when compared to ceramics $(9,10)$. On the other hand, cusp coverage with ceramics also has clinical disadvantages. Onlays and overlays involve a greater exposure of the restorative material to masticatory effects. The high elastic modulus makes ceramics brittle and susceptible to fatigue fracture. The potential of antagonist abrasion also has to be considered. Hence, an intracoronal restoration is preferable because it minimizes these effects and preserves the original occlusal contacts $(2-4,6,9,10)$.

There is no consensus in the literature concerning ceramic inlay, onlay and overlay cavity design, nor are there precise rules defining when cusps should be covered to transform inlays into overlays $(4-6,17)$. This study revealed no significant differences among intact, inlay and overlay groups when compressively loaded until fracture. In this study conditions, the teeth restored with ceramic inlays or overlays were as resistant to fracture as intact teeth.

Clinical studies $(15,17)$ have confirmed that teeth restored with ceramics with or without cusp coverage 
showed similar longevity. In a five-year follow-up study, van Dijken et al. (17) examined 182 ceramic restorations with 1) partial coverage without capping cusps, 2) partial coverage with some (but not all) cusps being capped, and 3) complete cusp capping, and no significant difference was observed when different preparation designs were compared. Consequently, conservative ceramic restorations reduce the need for traditional full-coverage therapy. Another study (15) investigated the influence of tooth preparation design on the long-term survival of 1444 ceramic restorations (over 14 years), and no statistically significant difference was observed between the survival rate of inlays (90\%) and onlays (96\%).

Considering the mode of fracture for inlays and overlays, most fractures (70\%) were classified as simple (Mode I), causing little damage to the restoration and to the tooth. If ceramic fracture had occurred in vivo, teeth restored with inlays could be repaired maintaining cusps intact, or, in a worst case scenario, the inlay could be replaced by an onlay or an overlay. However, if small fractures occur in teeth restored with overlays, a repair may still be possible, but cusps would already have been reduced and an overlay could only be replaced by another overlay. Since mode of fracture and fracture resistance were similar in the inlay and overlay groups, an inlay should be the first choice because the preparation is more conservative, preserving esthetics and occlusion, and because weakened cusps can be strengthened by adhesive luting (2-4,9,10,14-17).

These data are consistent with those of clinical studies that have reported a high success rate of adhesively luted ceramic inlays, onlays and overlays over 4-5 years $(14,16,17)$. Furthermore, a correlation between cusp reconstruction and ceramic fractures was not apparent (16).

Some limitations of this study must be mentioned. The compressive test alone cannot simulate clinical conditions. Other in vitro tests, such as stress distribution analysis, tension tests and clinical studies should be developed to determine longevity of various ceramic restorations with and without cusp coverage.

In this study, ceramic inlays reinforced the dental structure of teeth that were prepared with $1 / 2$ of the intercuspal width, obtaining stiffness values that were similar to those of intact teeth and teeth restored with ceramic overlays. The classic indication (18) for cusp coverage when the occlusal isthmus width is $1 / 3$ or more of the intercuspal distance should thus be reviewed, especially for bonded ceramic restorations. Considering the importance of the issue addressed in this study and the fact that few studies are found in literature, the present study was intended to contribute to elucidating the factors involved in fracture resistance of inlay and overlay restorations. Further research and long-term investigations are necessary to confirm in vitro results under clinical conditions.

Within the limitations of this study and according to the obtained results, it may be concluded that inlays and overlays showed cusp stiffness comparable to that of intact teeth. Modes of fracture for inlays and overlays were similar ( $70 \%$ of simple fracture). Class II MOD preparations with $1 / 2$ of the intercuspal distance did not require cusp coverage to protect them when bonded ceramic restorations were used. Inlays showed fracture strength values similar to those of overlays. Bonded ceramic inlays were similar to bonded ceramic overlays as regards fracture strength.

\section{RESUMO}

Este estudo avaliou a resistência à fratura de dentes restaurados com inlays e overlays de cerâmicas comparadas a dentes íntegros. Trinta pré-molares humanos íntegros foram divididos em 3 grupos: 1-Dentes sem preparo cavitário (controle), 2-Inlays e 3-Overlays. O preparo para as inlays apresentava uma cavidade de Classe II MOD tendo caixa oclusal com largura de metade da distância intercuspídica. O preparo para as overlays era semelhante ao das inlays; porém com cobertura das cúspides vestibular e palatina. Os grupos 2 e 3 foram restaurados com porcelanas feldspáticas fixadas com cimento resinoso. As amostras foram submetidas à compressão até a fratura. Os valores médios de fratura $(\mathrm{KN})$ foram: grupo $1=1,17$, grupo $2=1,17$ e grupo $3=1,14$. $O$ teste de Kruskal-Wallis não revelou diferença estatisticamente significante entre os 3 grupos ( $\mathrm{p}>0,05)$. Para as inlays e overlays, a predominância das fraturas envolveu fragmentos de uma das cúspides ( $70 \%$ de fraturas simples). Concluiu-se que os dentes restaurados com inlays e overlays apresentaram resistência da cúspide comparável aos dentes intactos.

\section{REFERENCES}

1. Esquivel-Upshaw JF, Anusavise KJ. Ceramic design concepts based on stress distribution analysis. Compend Contin Educ Dent 2000;21:649-654.

2. Burke FJT, Wilson NHF, Watts DC. The effect of cuspal coverage on the fracture resistance of teeth restored with indirect composite resin restorations. Quintessence Int 1993;24:875-880.

3. Brunton PA, Cattell P, Burke FJT, Wilson NHF. Fracture resistance of teeth restored with onlays of three contemporary tooth-colored resin-bonded restorative materials. J Prosthet Dent 1999;82:167171.

4. Magne P, Belser UR. Porcelain versus composite inlays/onlays: 
effects of mechanical loads on stress distribution, adhesion, and crown flexure. Int J Periodontics Restorative Dent 2003;23:543555.

5. Soares CJ, Martins LRM, Fonseca RB, Correr-Sobrinho L, Fernandes Neto AJ. Influence of cavity preparation design on fracture resistance of posterior leucite-reinforced ceramic restorations. J Prosthet Dent 2006;95:421-429.

6. Habekost LV, Camacho GB, Pinto MB, Demarco FF. Fracture resistance of premolars restored with partial ceramic restoration and submitted to two different loading stresses. Oper Dent 2006;31:204-211.

7. Krifka S, Anthofer T, Fritzsch M, Hiller KA, Schmalz G, Federlin M. Ceramic inlays and partial ceramic crowns: influence of remaining cusp wall thickness on the marginal integrity and enamel crack formation in vitro. Oper Dent 2009;34:32-42.

8. Nathanson D. Etched porcelain restorations for improved esthetics, part II: onlays. Compend Contin Educ Dent 1987;8:105-110.

9. Jensen ME, Redford DA, Williams BT, Gardner F. Posterior etched-porcelain restorations: an in vitro study. Compend Contin Educ Dent 1987;8:615-622.

10. Ragauska A, Apse P, Kasjanovs V, Berzina-Cimdina L. Influence of ceramic inlays and composite fillings on fracture resistance of premolars in vitro. Stomatologija 2008;10:121-126.

11. Mondelli J, Sene F, Ramos RP, Benetti AR. Tooth structure and fracture strength of cavities. Braz Dent J 2007;18:131-140.

12. Eackle WS, Maxwell EH, Braly BV. Fractures of posterior teeth in adults. J Am Dent Assoc 1986;112:215-218.
13. St-George AJ, Sturdevant JR, Swift Jr EJ, Thompson JY. Fracture resistance of prepared teeth restored with bonded inlay restorations. J Prosthet Dent 2003;89:551-557.

14. Stappert CF, Guess PC, Chitmongkolsuk S, Gerds T, Strub JR. All-ceramic partial coverage restorations on natural molars. Masticatory fatigue loading and fracture resistance. Am J Dent 2007;20:21-26.

15. Malament KA, Socransky SS. Survival of Dicor glass-ceramic dental restorations over 14 years. Part II: effect of thickness of Dicor material and design of tooth preparation. J Prosthet Dent 1999;81:662-667.

16. Krämer N, Frankenberger R, Pelka M, Petschelt A. IPS Empress inlays and onlays after four years - a clinical study. J Dent 1999;27:325-331.

17. Van Dijken JWV, Hasselrot L, Örmin L, Olofsson AL. Restorations with extensive dentin/enamel-bonded ceramic coverage. Eur J Oral Sci 2001;102:222-229.

18. Shillingburg Jr HT, Fisher DW. The MOD onlay - a rational approach to a restorative problem. N M Dent J 1970;21:12-14.

19. Fisher DW, Caputo AA, Shillingburg Jr. HT, Duncanson Jr MV. Photoelastic analysis of inlay and onlay preparations. J Prosthet Dent 1975;33:47-53

20. Dejak B, Mlotkowski A. Three-dimensional finite element analysis of strenght and adhesion of composite resin versus ceramic inlays in molars. J Prosthet Dent 2008;99:131-140.

Accepted May 18, 2009 